\title{
The Role of Patient Financial Assistance Programs in Reducing Costs for Cancer Patients
}

\author{
Leah L. Zullig, PhD; Steven Wolf, MS; Lisa Vlastelica, PharmD; \\ Veena Shankaran, MD; and S. Yousuf Zafar, MD
}

\begin{abstract}
BACKGROUND: Limited transparency exists regarding eligibility and benefits for patient financial assistance programs (PAPs).

OBJECTIVE: To describe oral anticancer medication costs, insurance coverage, and the degree of financial assistance provided by PAPs.

METHODS: This was a retrospective study of prescription anticancer medication costs and PAP coverage. The study used data from an academic cancer center's specialty pharmacy. Medication, cost, and coverage data were collected from the specialty pharmacy database for prescriptions filled from January 2013 to November 2015. Prescriptions with missing copayments, insurance, or financial assistance amounts were excluded. Descriptive statistics summarized prescription characteristics.
\end{abstract}

RESULTS: Of 9,388 anticancer medication prescriptions filled, 8,212 (87\%) had complete cost data and were included. The 5 most common medications prescribed were capecitabine $(20 \%)$, temozolomide (13\%), enzalutamide $(10 \%)$, letrozole $(6 \%)$, and tamoxifen $(4 \%)$. Most prescriptions were covered by commercial insurance or Part $D(41.6 \%, n=3,418)$. The median copayment was $\$ 20$ per prescription (interquartile range [IQR] $=\$ 10.00$ $\$ 80.30$ ). When considering all prescriptions that received PAP assistance, the median amount of financial assistance provided by PAPs per prescription was $\$ 411.0$ (IQR $=\$ 302.80-\$ 523.40$ ), amounting to $15 \%$ of the median prescription cash price. When considering all prescriptions, the median amount of financial assistance provided by PAPs per prescription was $\$ 0$, and the mean was $\$ 79.30(\mathrm{SD}=\$ 389.90)$.

CONCLUSIONS: A minority of prescriptions received financial assistance from PAPs. The proportion of financial assistance was small relative to the price billed to insurance. PAPs play a modest role in reducing anticancer prescription-related costs.

J Manag Care Spec Pharm. 2017;23(4):407-11

Copyright $\odot 2017$, Academy of Managed Care Pharmacy. All rights reserved.

\section{What is already known about this subject}

Oral anticancer medications (OAMs) are increasingly common. While OAMs may be more convenient for patients, they present unique challenges that include problems with medication adherence and cost.

Patient financial assistance programs (PAPs) may be a solution to increase affordability of OAMs

\section{What this study adds}

In this study, a minority of prescriptions received financial assistance from PAPs

Among prescriptions that received assistance from PAPs, the proportion of financial assistance was small relative to the price billed to insurance.

PAPs play a modest role in reducing OAM prescription-related costs.

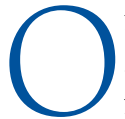
ral anticancer medications (OAMs) comprise nearly $30 \%$ of the oncology drug pipeline. ${ }^{1}$ Although OAMs may be more convenient for patients, ${ }^{2}$ potentially by reducing frequent clinic visits for intravenous chemotherapy administration, they also add unique challenges that include problems with daily medication adherence and, because of differences in insurance coverage for intravenous and oral cancer medications, increased out-of-pocket (OOP) costs., ${ }^{3,4}$ While there are many factors influencing costs related to cancer treatment, OAMs likely contribute to patients' treatment-related OOP costs. ${ }^{4,5}$ With regard to adherence with OAMs, patients are sensitive to small adjustments in OOP costs. ${ }^{6}$ Affording cancer care, including OAMs, often requires patients to alter their lifestyles or care choices, leverage their savings, and even declare personal bankruptcy. ${ }^{7-9}$ Financial toxicity, or the extreme financial burden often experienced as a side effect of cancer care, has been linked to a greater risk of mortality. ${ }^{10}$

OAMs may be an important driver of patient OOP cost because of insurance benefit design. Conventionally, anticancer medications are administered intravenously and are covered under major medical health insurance; however, coverage for OAMs typically fall under prescription drug plans. ${ }^{11}$ This coverage difference has important cost implications because OOP costs will vary depending on whether patients are responsible for copayments, coinsurance, and/or supplemental prescription medication coverage. In the case of OAMs, patients may need to purchase supplemental prescription drug coverage to reduce their OOP costs. However, many patients lack this type of prescription drug coverage.

Patient financial assistance programs (PAPs), sometimes called pharmaceutical assistance programs or prescription assistance programs, may be a complementary solution to bridge the coverage gap and reduce financial strain resulting 


\begin{tabular}{l|l}
\hline \multicolumn{1}{c|}{ TABLE 1 } & \multicolumn{1}{c}{ Key Definitions } \\
\hline Term & \multicolumn{1}{c}{ Definition } \\
\hline Cash price & $\begin{array}{l}\text { A reduced price offered to patients paying cash on } \\
\text { the day of their prescription fills. }\end{array}$ \\
\hline $\begin{array}{l}\text { Copayment amount } \\
\text { (copay) }\end{array}$ & $\begin{array}{l}\text { A fixed amount paid by the patient for a covered } \\
\text { health care service. }\end{array}$ \\
\hline Cost sharing & $\begin{array}{l}\text { When a patient pays a portion of costs for health } \\
\text { care services that are not covered by insurance. }\end{array}$ \\
\hline $\begin{array}{l}\text { Coverage paid by } \\
\text { a PAP }\end{array}$ & $\begin{array}{l}\text { The amount of the price billed to insurance that is } \\
\text { paid by the PAP on behalf of the patient over the } \\
\text { estimated cost of the drug at the cancer center. }\end{array}$ \\
\hline $\begin{array}{l}\text { Price billed to } \\
\text { insurance }\end{array}$ & $\begin{array}{l}\text { The amount that the health care provider charges } \\
\text { the insurance provider for the health care service. }\end{array}$ \\
\hline Insurance coverage & $\begin{array}{l}\text { The ratio of what the cancer center was paid by the } \\
\text { patient's primary insurance provider over the esti- } \\
\text { mated cost of the drug at the cancer center. }\end{array}$ \\
\hline PAP= patient financial assistance program.
\end{tabular}

from OAMs. Through PAPs, pharmaceutical manufacturers and patient support foundations diminish the financial impact of OAMs by offsetting patient out-of-pocket costs. By increasing drug accessibility and usage, pharmaceutical manufacturers stand to benefit from providing PAPs. ${ }^{12}$ However, there is insufficient evidence regarding the economic effect of PAPs from the perspectives of health care systems and patients. ${ }^{13}$ Because PAPs are often targeted at specific therapies and may or may not coordinate with insurers, patient financial support may be fragmented. Because of inconsistent eligibility criteria and complicated application processes, there is also limited transparency regarding eligibility for PAPs. Relatively little is known about the extent of financial assistance provided by PAPs to reduce costs for prescription anticancer drugs. ${ }^{14,15}$ The purpose of this study was to describe OAM costs, insurance coverage, and the degree of financial assistance provided by PAPs.

\section{Methods}

\section{Study Design}

This was a retrospective study of prescription OAM costs and PAP coverage at an academic cancer center's specialty pharmacy. The study was approved by the Duke University Institutional Review Board.

\section{Measures}

Using a specialty pharmacy database for oncology prescriptions filled for all cancer types treated at Duke University Medical Center, we collected information on prescriptions filled for OAMs from January 1, 2013, to November 30, 2015. Prescriptions with missing copayments, insurance, or financial assistance amounts were excluded. For included prescriptions, we collected the following measures: generic medication name, PAP coverage (binary measure), the percentage of coverage paid by a PAP, and the amount paid by the PAP. PAPs of all types were included (e.g., pharmaceutical manufacturer-sponsored PAPs and foundation-sponsored PAPs). We also collected information about the insurance type (e.g., uninsured, commercial, and Medicare Part D) used to cover the cost of the OAM, the copayment amount, the dollar amount charged by the referral cancer center, and the dollar amount reimbursed by the insurance provider to the referral cancer center. Key definitions are listed in Table 1.

\section{Statistical Analysis}

Analyses are presented by level of insurance coverage, since variance in costs is, by definition, dependent on type of insurance coverage (e.g., OAM fully covered by insurance [including coverage by insurance + PAP] vs. copayment required [coverage by insurance + PAP + copay]). Frequency distributions of the 5 most commonly prescribed OAMs are presented, and descriptive statistics were used to summarize characteristics of filled OAM prescriptions. Fisher's exact or chi-square tests for discrete variables and Kruskal-Wallis test for continuous variables were conducted to compare the differences between prescriptions that had no copayments versus prescriptions that required some amount to be paid. The unit of analysis was an individual prescription. Statistical analyses were performed using SAS version 9.4 (SAS Institute, Cary, NC).

\section{Results}

From January 1, 2013, to November 30, 2015, 9,388 OAM prescriptions were filled. We excluded prescriptions that had no documented payment $(\mathrm{n}=287)$, had a missing prescription number $(n=3)$ or $\$ 0$ drug price $(n=9)$, a missing patient identifier ( $n=2)$, or missing date of transaction ( $n=373$ ), since we could not determine if the prescription was filled during the study period. Additionally, we excluded 506 prescriptions where the payment exceeded the expected drug price. This resulted in 8,212 prescriptions for the analysis. The 5 most commonly prescribed OAMs were capecitabine $(20.4 \%, \mathrm{n}=1,672)$, temozolomide $(13.3 \%, n=1,088)$, enzalutamide $(10 \%, n=824)$, letrozole $(5.7 \%, n=467)$, and tamoxifen $(4.3 \%, n=351)$. Most prescriptions were insured through commercial plans and Medicare Part D (41.6\%, $\mathrm{n}=3,418)$. Other common insurance types were Medicaid/Medicare Part B $(22 \%, \mathrm{n}=1,807)$ and Medicare Part D alone $(31.6 \%, \mathrm{n}=2,591)$.

The median cash price charged by the specialty pharmacy was $\$ 2,762.10$ per prescription (interquartile range $[I Q R]=\$ 190.90-\$ 7,698.30$ ). The median amount covered by insurance was $\$ 2,627.90$ per prescription (IQR $=\$ 163.60$ $\$ 7,307.70)$. Twelve percent of prescriptions received financial assistance from PAPs, and of those, the vast majority (87\%) received assistance for less than $25 \%$ of the price charged by the specialty pharmacy. When considering all prescriptions that received PAP assistance, the median amount of financial assistance provided per prescription was $\$ 411.10$ 


\section{TABLE 2 Prescription Cost and Coverage by Copayment Status}

\begin{tabular}{|c|c|c|c|c|c|c|c|}
\hline \multirow[b]{2}{*}{ Any PAP coverage, $n(\%)$} & \multicolumn{2}{|c|}{$\begin{array}{l}\text { No Copay Amount } \\
(\mathrm{n}=3,091)\end{array}$} & \multicolumn{2}{|c|}{$\begin{array}{l}\text { Some Copay Amount } \\
\qquad(\mathrm{n}=5,121)\end{array}$} & \multicolumn{2}{|c|}{ Total $(\mathrm{N}=8,212)$} & \multirow{2}{*}{$\begin{array}{c}P \text { Value } \\
<0.0001^{a}\end{array}$} \\
\hline & 923 & $(29.9)$ & 28 & $(0.5)$ & 951 & $(11.6)$ & \\
\hline Primary insurance, $\mathbf{n}(\%)$ & & & & & & & $<0.0001^{\mathrm{a}}$ \\
\hline Missing & 15 & $(0.5)$ & 27 & $(0.5)$ & 42 & $(0.5)$ & \\
\hline Cash & 1 & $(0.0)$ & 160 & $(3.1)$ & 161 & $(2.0)$ & \\
\hline Commercial/Part D & 560 & $(18.1)$ & 2,858 & $(55.8)$ & 3,418 & $(41.6)$ & \\
\hline Copay card & 21 & $(0.7)$ & 13 & $(0.3)$ & 34 & $(0.4)$ & \\
\hline Grant/sponsor & 20 & $(0.6)$ & 126 & $(2.5)$ & 146 & $(1.8)$ & \\
\hline International patient & 0 & $(0.0)$ & 6 & $(0.1)$ & 6 & $(0.1)$ & \\
\hline Medicaid/Medicare B & 1,290 & $(41.7)$ & 517 & $(10.1)$ & 1,807 & $(22.0)$ & \\
\hline Part D & 1,181 & $(38.2)$ & 1,410 & $(27.5)$ & 2,591 & (31.6) & \\
\hline VA benefits & 3 & $(0.1)$ & 4 & $(0.1)$ & 7 & $(0.1)$ & \\
\hline Secondary insurance, $\mathrm{n}(\%)$ & & & & & & & $<0.0001^{a}$ \\
\hline Missing & 1,974 & $(63.9)$ & 4,731 & $(92.4)$ & 6,705 & $(81.6)$ & \\
\hline Cash & 14 & $(0.5)$ & 116 & $(2.3)$ & 130 & $(1.6)$ & \\
\hline Commercial & 47 & $(1.5)$ & 87 & $(1.7)$ & 134 & $(1.6)$ & \\
\hline Copay card & 38 & $(1.2)$ & 50 & $(1.0)$ & 88 & $(1.1)$ & \\
\hline Grant/sponsor & 862 & $(27.9)$ & 7 & $(0.1)$ & 869 & $(10.6)$ & \\
\hline Medicaid/Medicare B & 137 & $(4.4)$ & 118 & $(2.3)$ & 255 & $(3.1)$ & \\
\hline None & 7 & $(0.2)$ & 0 & $(0.0)$ & 7 & $(0.1)$ & \\
\hline Part D & 10 & $(0.3)$ & 11 & $(0.2)$ & 21 & $(0.3)$ & \\
\hline Sickle cell program & 2 & $(0.1)$ & 1 & $(0.0)$ & 3 & $(0.0)$ & \\
\hline PAP coverage, $n(\%)$ & & & & & & & $<0.0001^{b}$ \\
\hline $0 \%$ & 2,168 & $(70.1)$ & 5,093 & $(99.5)$ & 7,261 & $(88.4)$ & \\
\hline $0 \%-25 \%$ & 806 & $(26.1)$ & 20 & $(0.4)$ & 826 & $(10.1)$ & \\
\hline $25 \%-50 \%$ & 115 & (3.7) & 3 & $(0.1)$ & 118 & (1.4) & \\
\hline $50 \%-75 \%$ & 1 & $(0.0)$ & 1 & $(0.0)$ & 2 & $(0.0)$ & \\
\hline $75 \%-100 \%$ & 1 & $(0.0)$ & 4 & $(0.1)$ & 5 & $(0.1)$ & \\
\hline \multicolumn{8}{|l|}{ Copay amount } \\
\hline Mean (SD) & & & 148.5 & $(504.2)$ & & & \\
\hline Median & & & & & & & \\
\hline Quarter 1, Q3 & & & 10.0 & 80.3 & & & \\
\hline Range & & & $(0.0-5$ & $28.5)$ & & & \\
\hline PAP & & & & & & & $<0.0001^{c}$ \\
\hline Mean (SD) & 193.6 & $(511.1)$ & 10.3 & $(271.0)$ & 79.3 & $(389.9)$ & \\
\hline Median & & & & & & & \\
\hline Q1, Q3 & 0.0 & 94.0 & & & & & \\
\hline Range & $(0.0-$ & $432.2)$ & $(0.0-1$ & 288.1) & $(0.0-1)$ & 288.1) & \\
\hline What the cancer center was paid by the primary insurance & & & & & & & $<0.0001^{\mathrm{c}}$ \\
\hline Mean (SD) & $4,610.1$ & $3,641.6)$ & $3,500.8$ & $(4,017.1)$ & $3,918.3$ & $3,916.8)$ & \\
\hline Median & & & & & & & \\
\hline Q1, Q3 & $1,865$. & $7,692.3$ & 33.0 & 883.0 & 163.6 & 307.7 & \\
\hline Range & $(4.3-2$ & 805.2) & $(0.0-2$ & 090.3) & $(0.0-2$ & 090.3) & \\
\hline Drug cash price at the cancer center & & & & & & & $<0.0001^{\mathrm{c}}$ \\
\hline Mean (SD) & $4,837.9$ & $3,738.8)$ & $3,678.7$ & $4,121.9)$ & $4,115.0$ & $4,021.3)$ & \\
\hline Median & & & & & & & \\
\hline Q1, Q3 & $1,974.6$ & $8,119.6$ & 57.1, & 299.8 & 190.9 & 698.3 & \\
\hline Range & $(6.0-2$ & $805.2)$ & (1.6-2 & 140.3) & $(1.6-2$ & 140.3) & \\
\hline
\end{tabular}

aChi-square test.

${ }^{b}$ Fisher exact test.

cKruskal Wallis test.

$P A P=$ patient financial assistance program; $Q=$ quartile; $S D=$ standard deviation; VA=Veterans Affairs. 
(IQR $=\$ 302.80-\$ 523.40)$, which amounted to $15 \%$ of the median prescription cash price.

When considering all prescriptions (those that received and did not receive PAP assistance), the median amount of financial assistance provided by PAPs per prescriptions was $\$ 0$, and the mean was $\$ 79.30$ (standard deviation $=\$ 389.90$ ). Prescriptions filled with Part D most commonly received financial assistance (78.2\% of all prescriptions with some level of PAP coverage). The median reimbursement for drugs was higher for patients who were fully covered $(\$ 3,169.30$ vs. $\$ 1,967.00, P<0.0001)$. Drugs were more expensive in the fully covered group (median $=\$ 3,304.9$ vs. $\$ 2,224.80, P<0.0001$; Table 2).

More than half of the prescriptions $(62.4 \%, n=5,121)$ had some copayment amount. Prescriptions with no copayment were more likely to have received some level of financial assistance ( $29.9 \%$ vs. $0.5 \%, P<0.0001)$. Prescriptions with no copayments also were more likely to have had between $0 \%$ and $25 \%$ of PAP coverage ( $26.1 \%$ vs. $0.4 \%$ ). The median copay was $\$ 20$ per prescription $(\mathrm{IQR}=\$ 10.00-\$ 80.30)$.

\section{Discussion}

In this study, PAPs played a relatively small role in reducing the cost of OAM prescriptions. Few patients received PAP assistance, and among those who did, PAPs covered only a small proportion of OOP costs.

A key reason for the high cost burden associated with OAMs is health insurance benefit design. Insurers generally cover intravenously administered chemotherapy as a medical benefit. Orally administered chemotherapy is treated differently. OAMs are treated as a prescription drug benefit. Instead of being responsible for a copay, patients are responsible for paying a high percentage of the medication cost (i.e., cost sharing), and an annual OOP maximum may not apply. Additionally, most OAMs are placed on specialty tiers of drug formularies, often even generics, which demand a greater coinsurance and costsharing burden for patients. Placing OAMs on specialty tiers introduces unnecessary confusion and cost barriers. Moreover, patients with cancer may be responsible for coinsurance on all aspects of their cancer care, and OAMs may be just a small part of their overall cancer care costs. For example, the use of intravenously administered anticancer medications has increased more dramatically than OAMs. ${ }^{4}$ In 2011, intravenously administered anticancer medications accounted for $63 \%$ of all chemotherapy expenditures. ${ }^{4}$

While PAPs are a helpful solution to help patients bridge their cancer care costs, they have been criticized for potentially increasing drug costs in the long run. PAPs may reduce OOP costs for select patients who can prove financial need and are filling prescriptions for certain high-priced drugs; however, PAPs may do so by shifting cost to health insurers. As drug prices soar, insurers peel back coverage as a result. ${ }^{16}$ Thus, PAPs may not be as helpful a strategy to reduce prescription cost as they appear on the surface.

Eligibility requirements for PAPs often lack transparency and may require an onerous application process in order to continue receiving assistance..$^{17,18}$ Patients with governmentfunded insurance coverage, such as Medicare, are ineligible to receive assistance from PAPs sponsored by pharmaceutical manufacturers. Because of concerns that industry-sponsored PAPs might be used by manufacturers to subsidize their own products, the U.S. Department of Health and Human Services Office of Inspector General has been tasked with assessing the appropriateness of industry-funded PAPs. ${ }^{19}$ However, the distinction between types of PAPs may be unclear. Many charitable foundations receive funding from pharmaceutical manufacturers and use these funds to provide financial assistance; Medicare enrollees are eligible to receive financial assistance from charitable foundation PAPs. ${ }^{20}$ Of note, our analysis included prescriptions from multiple insurance types and makes no distinction between pharma- and foundationsponsored PAPs.

\section{Limitations}

This study has several limitations that should be considered. Because this study was conducted at an academic medical center, our findings may not be generalizable. The unit of analysis was the prescription, so it was not possible to adjust for patient-level differences in PAP-seeking behavior or to evaluate patient eligibility for PAP participation. We were also unable to comment on patient OOP cost, which is of critical importance when considering the effect of PAPs. This is a key area for future research. It is worth noting that 2,109 prescriptions had a sum of copay, insurance, and PAP amount that was less than the expected drug price. Possibly, there were confounders present that we did not collect or account for in this analysis that could account for these discrepancies. Because this was a retrospective study, we were limited to discussing associations and not causations. Additionally, because we were using a database of prescriptions that were filled, we lacked information for patients who never filled their OAM prescriptions because of cost.

Despite these limitations, this study points to a key next step. There is a need for more research on how patients cope with OOP costs in the era of modern insurance design, when coinsurance and high deductible plans are the norm.

\section{Conclusions}

Despite high OAM prices, PAPs played a relatively small role in prescription medication cost reduction in this single-institution study. More work is needed to efficiently identify patients in need and match them with appropriate financial resources. 


\section{Authors}

LEAH L. ZULLIG, PhD, Durham Center for Health Services Research and Development in Primary Care and Division of General Internal Medicine, Department of Medicine, Duke University, Durham, North Carolina. STEVEN WOLF, MS, Department of Biostatistics and Bioinformatics; LISA VLASTELICA, PharmD, Department of Pharmacy; and S. YOUSUF ZAFAR, MD, Division of Medical Oncology, Department of Medicine, Duke University, Durham, North Carolina. VEENA SHANKARAN, MD, Division of Medical Oncology, Department of Medicine, University of Washington, Seattle.

AUTHOR CORRESPONDENCE: Leah L. Zullig, PhD, 411 W. Chapel Hill St., Ste. 600, Durham, NC 27701. Tel.: 919.286.6936; E-mail: leah.zullig@duke.edu.

\section{DISCLOSURES}

Support of this project by The Duke Biostatistics Core was made possible by Grant Number UL1TR001117 from the National Center for Advancing Translational Sciences (NCATS), a component of the National Institutes of Health (NIH), and NIH Roadmap for Medical Research. Zullig is supported by a VA Health Services Research and Development (HSR\&D) Career Development Award (CDA 13-025). Zullig also reports a financial relationship with Novartis. Zafar reports financial relationships with Novartis, GenentechRoche, and Vivor. Vlastelica, Shankaran, and Wolf have nothing to disclose. The views in this article are those of the authors and do not necessarily represent the views of the Department of Veterans Affairs, Duke University, NCATS, or NIH.

This abstract was previously presented at the 2016 ASCO Annual Meeting; Chicago, Illinois; June 3-7, 2016.

Study concept and design were contributed by Zafar, Zullig, and Vlastelica, with assistance from Shankaran. Vlastelica and Wolf took the lead in data collection, along with Zafar, and data interpretation was performed by Zullig, Zafar, and Wolf, along with Vlastelica and Shankaran. The manuscript was written and revised by Zullig and Zafar, along with the other authors.

\section{REFERENCES}

1. Weingart SN, Brown E, Bach PB, et al. NCCN Task Force Report: oral chemotherapy. J Natl Compr Canc Netw. 2008;6(Suppl 3):S1-14.

2. Schott S, Schneeweiss A, Reinhardt J, et al. Acceptance of oral chemotherapy in breast cancer patients-a survey study. BMC Cancer. 2011;11:129.

3. Greer JA, Amoyal N, Nisotel L, et al. A systematic review of adherence to oral antineoplastic therapies. Oncologist. 2016;21(3):354-76.

4. Shih YC, Smieliauskas F, Geynisman DM, Kelly RJ, Smith TJ. Trends in the cost and use of targeted cancer therapies for the privately insured nonelderly: 2001 to 2011. J Clin Oncol. 2015;33(19):2190-96.
5. Bennette CS, Richards C, Sullivan SD, Ramsey SD. Steady increase in prices for oral anticancer drugs after market launch suggests a lack of competitive pressure. Health Aff (Millwood). 2016;35(5):805-12.

6. Dusetzina SB, Winn AN, Abel GA, Huskamp HA, Keating NL. Cost sharing and adherence to tyrosine kinase inhibitors for patients with chronic myeloid leukemia. J Clin Oncol. 2014;32(4):306-11.

7. Bestvina CM, Zullig LL, Yousuf Zafar S. The implications of out-of-pocket cost of cancer treatment in the USA: a critical appraisal of the literature. Future Oncol. 2014;10(14):2189-99.

8. Nipp RD, Zullig LL, Samsa G, et al. Identifying cancer patients who alter care or lifestyle due to treatment-related financial distress. Psychooncology. 2016;25(6):719-25.

9. Ramsey S, Blough D, Kirchhoff A, et al. Washington State cancer patients found to be at greater risk for bankruptcy than people without a cancer diagnosis. Health Aff (Millwood). 2013;32(6):1143-52.

10. Ramsey SD, Bansal A, Fedorenko CR, et al. Financial insolvency as a risk factor for early mortality among patients with cancer. J Clin Oncol. 2016;34(9):980-86.

11. Kircher SM, Meeker CR, Nimeiri H, et al. The parity paradigm: can legislation help reduce the cost burden of oral anticancer medications? Value Health. 2016;19(1):88-98.

12. Howard DH. Drug companies' patient-assistance programs-helping patients or profits? New Engl J Med. 2014;371(2):97-99.

13. Felder TM, Palmer NR, Lal LS, Mullen PD. What is the evidence for pharmaceutical patient assistance programs? A systematic review. J Health Care Poor Underserved. 2011;22(1):24-49.

14. Chisholm MA, DiPiro JT. Pharmaceutical manufacturer assistance programs. Arch Intern Med. 2002;162(7):780-84.

15. Zafar Y, Asabere A, Bastian A. Oncology patient assistance programs (PAPs): A first-in-kind analysis of U.S. drug manufacturer program benefits and eligibility requirements. Eur J Cancer. 2015;51(Suppl 3):S176 [Abstract 1213]. Available at: http://www.ejcancer.com/article/S0959-8049(16)305172/abstract. Accessed February 25, 2017.

16. Ubel PA, Bach PB. Copay assistance for expensive drugs: a helping hand that raises costs. Ann Intern Med. 2016;165(12):878-79.

17. Choudhry NK, Lee JL, Agnew-Blais J, Corcoran C, Shrank WH. Drug company-sponsored patient assistance programs: a viable safety net? Health Aff (Millwood). 2009;28(3):827-34.

18. Felder TM, Bennett CL. Can patients afford to be adherent to expensive oral cancer drugs? Unintended consequences of pharmaceutical development. J Oncol Pract. 2013;9(6 Suppl):64s-66s. Available at: http://ascopubs. org/doi/pdf/10.1200/JOP.2013.001167. Accessed February 25, 2017.

19. Rutherford C. OIG Continues to refine guidance on patient assistance programs. The National Law Review. February 23, 2016. Available at: http:// www.natlawreview.com/article/oig-continues-to-refine-guidance-patientassistance-programs. Accessed February 25, 2017.

20. Elgin B, Langreth R. How big pharma uses charity programs to cover for drug price hikes: a billion-dollar system in which charitable giving is profitable. BloombergBusinessweek. May 19, 2016. Available at: http://www. bloomberg.com/news/articles/2016-05-19/the-real-reason-big-pharmawants-to-help-pay-for-your-prescription. Accessed February 25, 2017. 